University of Wollongong

Research Online

Faculty of Engineering and Information

Faculty of Engineering and Information

Sciences - Papers: Part A

Sciences

$1-1-2016$

\title{
Biomethane potential evaluation of co-digestion of sewage sludge and organic wastes
}

Richard Wickham

University of Wollongong, rw259@uowmail.edu.au

Brendan Galway

Sydney Water Corporation

Heriberto A. Bustamante

Sydney Water Corporation, heri.bustamante@sydneywater.com.au

Long D. Nghiem

University of Wollongong, longn@uow.edu.au

Follow this and additional works at: https://ro.uow.edu.au/eispapers

Part of the Engineering Commons, and the Science and Technology Studies Commons

Research Online is the open access institutional repository for the University of Wollongong. For further information contact the UOW Library: research-pubs@uow.edu.au 


\title{
Biomethane potential evaluation of co-digestion of sewage sludge and organic wastes
}

\begin{abstract}
Co-digestion of organic rich wastes and wastewater sludge to enhance biogas production has become an attractive economic possibility for water utilities. The suitability of the organic rich waste depends on its ability to produce biogas as well as its influence on the overall anaerobic digestion process. Biomethane potential evaluation was conducted to screen seven organic wastes and dehydrated algae. All cosubstrates increased the bio-methane yield by three to six times compared with conventional anaerobic digestion of sewage sludge. Maximum co-digestion ratios were identifiable for most solid co-substrates including algae ( $6 \% \mathrm{wt} / \mathrm{wt})$, undiluted food waste ( $5 \% \mathrm{wt} / \mathrm{wt})$, bakery waste $(5 \% \mathrm{wt} / \mathrm{wt})$, and diluted commercial food waste ( $10 \% \mathrm{wt} / \mathrm{wt})$. On the other hand, the maximum co-digestions ratio of beverage reject and sewage sludge was $10 \%$ (wt/wt). With the exception of fat-oil-grease, all solids free liquid cosubstrates evaluated in this study showed a notable synergistic effect, to enhanced removals of total solids, volatile solids (VS) and chemical oxygen demand (COD) during anaerobic digestion. The increase in COD removal when co-digesting wastewater sludge and liquid waste was from 2 to $41 \%$. Conversely, the co-digestion of most solid co-substrates resulted in additional VS and COD residuals in the final biosolids. Elevated concentrations of sulphur and phosphorous in all food waste co-substrates suggest that control measures to address $\mathrm{H} 2 \mathrm{~S}$ in biogas and the accumulation of phosphorus in sludge centrate may be necessary during full scale operation. Data presented here provide the basis for subsequent pilot scale evaluation of anaerobic digestion of these organic rich wastes and wastewater sludge.
\end{abstract}

\section{Keywords}

organic, sludge, sewage, digestion, co, evaluation, wastes, potential, biomethane

\section{Disciplines}

Engineering | Science and Technology Studies

\section{Publication Details}

Wickham, R., Galway, B., Bustamante, H. \& Nghiem, L. D. (2016). Biomethane potential evaluation of codigestion of sewage sludge and organic wastes. International Biodeterioration and Biodegradation, 113 3-8. 
1 Biomethane potential evaluation of co-digestion of sewage sludge and organic wastes

Revised Manuscript Submitted to

Richard Wickham ${ }^{\mathrm{a}}$, Brendan Galway ${ }^{\mathrm{b}}$, Heriberto Bustamante ${ }^{\mathrm{b}}$, and Long D. Nghiem *,a

${ }^{\text {a }}$ Strategic Water Infrastructure Laboratory, School of Civil Mining and Environmental Engineering, University of Wollongong, Wollongong, NSW 2522, Australia

${ }^{\mathrm{b}}$ Sydney Water, Parramatta, NSW 2124, Australia

10 *Corresponding author. Email: longn@uow.edu.au. 


\section{Abstract}

12 Co-digestion of organic rich wastes and wastewater sludge to enhance biogas production has 13 become an attractive economic possibility for water utilities. The suitability of the organic 14 rich waste depends on its ability to produce biogas as well as its influence on the overall anaerobic digestion process. Biomethane potential evaluation was conducted to screen seven organic wastes and dehydrated algae. All co-substrates increased the bio-methane yield by three to six times compared with conventional anaerobic digestion of sewage sludge. Maximum co-digestion ratios were identifiable for most solid co-substrates including algae $(6 \% \mathrm{wt} / \mathrm{wt})$, undiluted food waste $(5 \% \mathrm{wt} / \mathrm{wt})$, bakery waste $(5 \% \mathrm{wt} / \mathrm{wt})$, and diluted commercial food waste $(10 \% \mathrm{wt} / \mathrm{wt})$. On the other hand, the maximum co-digestions ratio of beverage reject and sewage sludge was $10 \%(\mathrm{wt} / \mathrm{wt}$ ). With the exception of fat-oil-grease, all liquid co-substrates evaluated in this study showed a notable synergistic effect, to enhanced removals of total solids, volatile solids (VS) and chemical oxygen demand (COD) during anaerobic digestion. The increase in COD removal when co-digesting wastewater sludge and liquid waste was from 2 to $41 \%$. Conversely, the co-digestion of most solid co-substrates resulted in additional VS and COD residuals in the final biosolids. Elevated concentrations of sulphur and phosphorous in all food waste co-substrates suggest that control measures to address $\mathrm{H}_{2} \mathrm{~S}$ in biogas and the accumulation of phosphorus in sludge centrate may be necessary during full scale operation. Data presented here provide the basis for subsequent pilot scale evaluation of anaerobic digestion of these organic rich wastes and wastewater 31 sludge.

Keywords: biomethane potential (BMP), co-digestion, organic wastes, anaerobic digestion, 33 biogas production.

\section{Introduction}

Anaerobic digestion is an essential process in wastewater treatment, involving the use of microorganisms to break down organic material in the absence of oxygen (Tchobanoglous and Burton, 1991). Traditional anaerobic digestion applications focus on the stabilisation and volume reduction of sewage sludge produced in primary and secondary treatment of municipal wastewater. However, evolving social values and economic considerations have prompted an objective scope expansion. This additional scope includes the utilization of the biogas which is a product of the anaerobic digestion process for beneficial use. 
Biogas represents a renewable energy resource for the industry (Esposito et al., 2012). It composes of about $60 \% \mathrm{CH}_{4}, 40 \% \mathrm{CO}_{2}$, and a few trace gases such as $\mathrm{H}_{2} \mathrm{~S}$ and water vapour (Chynoweth et al., 2001; Tchobanoglous and Burton, 1991). Biogas can be readily converted to electrical and thermal energy via a co-generator, typically for onsite consumption (Shen et al., 2015; Tchobanoglous and Burton, 1991).

In Australia, biogas is still a largely underutilised resource due to a range of unfavourable economic and policy factors (Edwards et al., 2015a). Energy production from biogas does not qualify for a feed-in-tariff in all states in Australia with the exception of Victoria, where systems smaller than $100 \mathrm{KW}$ are eligible to receive 0.068 AUD $\$ / \mathrm{kWh}$ (Edwards et al., 2015b). The maintenance cost of co-generation in Australia is high regardless of their size. Thus, small scale energy recovery systems tend to be economically infeasible. In Australia, rebates for renewable energy production from biogas of 0.038 AUD $\$ / \mathrm{kWh}$ are only available to large scale producers through the Large-scale Generation Certificates (LGCs) scheme under the Renewable Energy Target policy (Edwards et al., 2015b). As a result, there is a critical scale of biogas production above which biogas utilisation can be economically feasible. This critical threshold can be overcome through the use of co-digestion of the sewage sludge with concentrated organic wastes (Fersi et al., 2014; Silvestre et al., 2015). Sewage sludge is ideal for use as the base substrate in co-digestion due to its low concentrations of inhibitors and high alkalinity (Mata-Alvarez et al., 2014). In addition, anaerobic digestion facilities are readily available at most wastewater treatment plants.

Co-digestion offers several benefits over traditional mono-digestion when applied (MataAlvarez et al., 2014; Pavan et al., 2007; Wang et al., 2013). Beyond the improvements to biogas production, co-digestion facilitates the optimisation of digester stoichiometry, which can positively influence digestion performance with respect to sludge degradation. In other words, by adding a carbon rich organic waste co-substrate to wastewater sludge (which usually has a low $\mathrm{C}: \mathrm{N}$ ratio), an optimum $\mathrm{C}: \mathrm{N}$ ratio for anaerobic digestion can be obtained.

The economic viability of co-digestion can be significantly enhanced through the contribution of supplementary revenue from gate fees (i.e. commercial charges for waste disposal). In Australia, once the generation capacity reaches $1 \mathrm{MW}$, there can be additional revenue from LGCs as noted above. Co-digestion substantially improves the sustainability of waste management practices (Kim and Kim, 2010). In particular, co-digestion allows the 
diversion of solid organic wastes from landfill, thus limiting greenhouse gas emission while facilitating energy recovery through biogas production (Holm-Nielsen et al., 2009).

75

76

Despite the active attempts to optimize co-digestion, there remain several technological challenges associated with its implementation (Giuliano et al., 2013; Haider et al., 2015; Koch et al., 2015b; Mata-Alvarez et al., 2014). Uncertainty related to the potential implications of co-digestion on biosolids (dewatered digested sludge) quality and volume are considerable due to the proportionality of their disposal costs, which account for a significant proportion of overall wastewater treatment expenditures (Appels et al., 2008). Poor cosubstrate selection and excessive co-digestion can also instigate digester inhibition, often through the introduction of inhibitory substances and overloading of organic ratios. Additionally, the presence of sulphur can facilitate the formation of $\mathrm{H}_{2} \mathrm{~S}$ (Dewil et al., 2009; Park et al., 2014). High $\mathrm{H}_{2} \mathrm{~S}$ concentration in biogas can damage combustion engine components and piping (Weiland, 2010). Excessive phosphorous in AD can cause struvite precipitation on pipelines, valves and other plant infrastructure (Sabbag et al., 2015).

This study aims to screen seven carbon rich organic wastes with regards to their potential use as co-substrates for further biogas production. Bio-methane potential (BMP) assessment and co-substrate characterisation are conducted for comparative analysis of organic wastes with varying compositions. Data obtained from this study will be used to design a pilot scale study to assess the anaerobic digestion of these organic rich wastes and wastewater sludge.

\section{Materials and Methods}

\subsection{Wastewater Sludge and Co-substrates}

Sludge from a full scale anaerobic digester at the Wollongong wastewater treatment plant (WWTP) was used as the inoculum and sludge co-substrate. The organic co-substrates were categorized into either solid (or slurry) and free-flowing (solids free) liquid materials. All organic co-substrates were collected fresh and were stored at $4{ }^{\circ} \mathrm{C}$ for less than three days prior to BMP evaluation.

The solid organic wastes included municipal food waste from a local council in Sydney Australia (denoted as RW-FW), commercial food waste from a commercial waste collector (denoted as PM-FW), paper pulp reject (denoted as PW), and untreated waste from a bakery (denoted as UBW). Food waste (RW-FW) from the local council was macerated into slurry without any water addition. Food waste from the commercial waste collector (PM-FW) was 
macerated with water as part of their collection process. These two types of food waste were both sampled on two separate occasions to assess their temporal variability. Paper pulp reject was cellulose in powder form from a paper mill in New South Wales, Australia. Untreated bakery waste was from a large bread making factory in Sydney Australia and was in the form of thickened slurry.

109 In addition to the solid organic wastes, dehydrated Ulva macroalgae powder from Venus

110 Shell Systems (Australia) was also evaluated for comparison purposes as it has been a widely 111 used substrate for anaerobic digestion as noted in several recent reviews (McKennedy and 112 Sherlock, 2015; Montingelli et al., 2015). These algae are not a waste product but are 113 abundant in coastal area in Australia. The chemical composition of dehydrated Ulva 114 macroalgae has been systematically described elsewhere (Yaich et al., 2011). Briefly, it 115 contains approximately $54.9 \%$ carbohydrate, $10.0 \%$ uronic acid, $8.5 \%$ protein, and $7.9 \%$ 116 lipid. The ash content of Ulva macroalgae is about 19.6\% (Yaich et al., 2011). It is 117 noteworthy that the lignin (non-degradable) fraction in the carbohydrate of Ulva macroalgae 118 is very low (about 1\%) (Montingelli et al., 2015).

119 The liquid organic wastes included non-alcoholic beverage reject (denoted as BJ), pre-treated organic waste from the same bakery as mentioned above (denoted as TBW), fat-oil-grease 121 (FOG) from a commercial waste collector, and waste from an industrial dairy processor (denoted as DW).

\subsection{Biomethane Potential Experimental Equipment}

124 The co-digestion of sludge and organic co-substrate was evaluated using a customised BMP system (Nghiem et al., 2014). The BMP system included an array of $1 \mathrm{~L}$ fermentation glass bottles (Wiltronics Research Pty Ltd) and a gas collection gallery (Fig. 1). The fermentation bottles were submerged in a water bath (Model SWB20D, Ratek Instrument Pty Ltd) to maintain a constant temperature of $35.0 \pm 0.1{ }^{\circ} \mathrm{C}$. Each bottle setup comprised of a rubber stopper, a water-filled S-shaped airlock, and a valve. Biogas from the bottle could flow

130 through the airlock into the gas collector via flexible plastic tubing. The gas collector was an inverted plastic measuring cylinder $(1000 \mathrm{~mL})$, which was initially filled with, and partially submerged in, a $1 \mathrm{M} \mathrm{NaOH}$ solution. 


\subsection{Experimental Protocol}

135 Prior to all BMP experiment, fermentation bottles were flushed with pure $\mathrm{N}_{2}$ for 5 minutes 136 before filling with $750 \mathrm{~mL}$ of organic co-substrate and inoculum (section 2.1). A set of BMP 137 experiments using partially digested sludge as the only substrate was also conducted as a 138 reference. After filling with the substrate, the bottle was flushed again with $\mathrm{N}_{2}$ and 139 immediately sealed with the rubber stopper. They were then placed into the shaking water 140 bath and the valve was opened to allow biogas to enter the gas collection gallery.

141 To measure the volume of $\mathrm{CH}_{4}$ generated from the BMP bottle, the cylinder was first filled 142 with $1 \mathrm{M} \mathrm{NaOH}$ solution, and was inverted and then partially submerged into a container also 143 containing $1 \mathrm{M} \mathrm{NaOH}$. Biogas from the fermentation bottle was introduced into the 144 submerged part of the cylinder, thus allowing the $\mathrm{NaOH}$ solution to absorb $\mathrm{CO}_{2}$ and $\mathrm{H}_{2} \mathrm{~S}$ 145 from the biogas. The remaining $\mathrm{CH}_{4}$ gas displaced the $\mathrm{NaOH}$ solution inside cylinder and the $146 \mathrm{CH}_{4}$ gas volume generated was recorded daily. The experiment was terminated when less 147 than $5 \mathrm{~mL} /$ day of $\mathrm{CH}_{4}$ was produced.

148 All BMP experiments were conducted in duplicate. With the exception of the algae (which 149 were assessed over a wider range of concentrations), all co-substrates were co-digested with 150 sludge in concentrations of 5,10 and $15 \%$ by weight.

\subsection{Analytical Methods}

152 A range of parameters were measured for the co-substrates, sludge and sludge/co-digestion 153 mixtures before and after the BMP experiment. Total chemical oxygen demand (COD) was 154 measured using a Hatch DRB200 COD Reactor and Hatch DR3900 spectrophotometer 155 (program number 435 COD HR) following the US-EPA Standard Method 5220 with a 156 dilution factor of 10. Total solids (TS), volatile solids (VS), $\mathrm{pH}$, conductivity and alkalinity 157 were conducted within 3 days of collecting the samples. Samples were preserved at $4{ }^{\circ} \mathrm{C}$. 158 Further details of these analyses are available elsewhere (Yang et al., 2016). Total sulphur 159 and total phosphorous were analysed within 24 hours by Sydney Water's NATA accredited 160 West Ryde Analytical Laboratory.

\subsection{VS Reduction Calculation}

162 The removal efficiencies used in digestion performance evaluation for all co-substrates were 163 calculated using the following equation: 


$$
\text { Reduction }=100 \times\left(1-\frac{C_{\text {CoEnd }}-C_{I E n d}}{C_{\text {CoIni }}-C_{I E n d}}\right)
$$

165 Where $\mathrm{C}_{\mathrm{CoEnd}}$ is the concentration of volatile solids in the co-digested sample at the end of the

166 BMP test; $\mathrm{C}_{\text {CoIni }}$ is the concentration of the co-digested sample at the beginning of the test; 167 and $\mathrm{C}_{\mathrm{IEnd}}$ is the post-digestion concentration of the inoculum. A reduction of $100 \%$ indicates 168 that the co-substrate is expected to contribute no residuals of this parameter. Greater than $169100 \%$ removal demonstrates a synergistic digestion of the co-substrate and sewage sludge, 170 indicating that the co-substrate can positively impacts on the digestion performance in the 171 sludge.

\section{3. Results and Discussion}

\section{$173 \quad 3.1 \quad$ Co-substrate Characteristics}

174 The primary characteristics of the wastewater sludge from Wollongong WWTP, individual co-substrates are collated in Table 1. A clear distinction between solid and liquid cosubstrates was the significantly higher TS and VS contents in the former. An exception to this was the commercial food waste (PM FW-2) sample, which could be due to water dilution as noted in section 2.1. The implication of the higher solids content is a greater propensity to contribute to biosolids production in the downstream processes. Further notable characteristics concern the concentrations of sulphur and phosphorus measured in the food waste co-substrates compared with the wastewater sludge.

\section{[TABLE 1]}

183 Co-substrate selection also fringes upon sourcing factors. With the exception of the algae, all other co-substrates are essentially waste materials. As a result, there can be significant temporal and spatial variation in their properties. Indeed, notable variation can be observed in the composition of the municipal (RW-FW) and commercial (PM-FW) food waste samples between the two sample occasions (Table 1).

\subsection{Co-digestion with Algae}

189 It is noteworthy that the algae used in this study are not a waste material. Given their

190 consistency in carbohydrate and lipid content (section 2.1), they were used as a reference

191 organic material. The algae co-substrate was mixed with the wastewater sludge on a mass 192 fraction percentage (dry waste of algae over total weight of the substrate) over a range of 193 concentrations from $0.25-9 \%$ (wt/wt). 
194 Figure 2 shows the cumulative methane production increased as the algae fraction increased to $6 \%(\mathrm{wt} / \mathrm{wt})$. Above the optimum point the introduction of additional co-substrate was inhibitive to overall methane production. The trend is further demonstrated in Figure 3, which shows a sharp decline in production beyond the optimum $6 \%(\mathrm{wt} / \mathrm{wt})$ algae concentration.

198 The inhibition of the anaerobic system was attributed to organic overloading. A high 199 carbon/nitrogen stoichiometric ratio resulted in excessive production and thus build-up of volatile fatty acids. Fatty acid accumulation leads to $\mathrm{pH}$ decrease, subsequently inhibiting microbiological function (Prochazka et al., 2012). Within the algae fraction of $6 \%$ or below, the addition of the co-substrate did not cause an excessive build-up of volatile fatty acids and there was sufficient time for the produced acids to be digested.

\section{[FIGURE 2]}

The removals of TS and VS were found to be approximately $59 \%$ and $75 \%$ respectively for the algae co-substrate samples. These results indicate that the use of algae as a co-substrate would lead to additional biosolids production. The methane potential of the algae co-substrate was approximately $139 \mathrm{~L} \mathrm{CH}_{4} / \mathrm{kg}$ of co-substrate.

\subsection{Co-digestion with Solid Wastes}

211 All organic waste co-substrates increased the methane yield above that of only wastewater 212 sludge. However, organic over loading was observed for municipal food waste (RW-FW) at 213 both sampling occasions when the co-digestion ratio was 10 and 15\% (wt/wt) (Figure 4a). 214 Indeed, biogas production was substantially lower when the co-digestion ratio was 5\% 215 (Figure 4a). Anaerobic digestion inhibition was also observed with untreated bakery waste 216 (UBW) at the co-digestion ratio of 10 and 15\% (data not shown). Similar to the results from 217 algae (section 3.2), the observed inhibition at high municipal food waste (RW-FW) and 218 untreated bakery waste (UBW) co-digestion ratios was attributed to the build-up of volatile 219 organic acids, evidenced by a low $\mathrm{pH}$ (less than 5) of the substrate at the end of the experiments of all BMP bottles with poor methane production (Li et al., 2015).

221 Temporal variability of VS and COD of the municipal food waste (RW-FW) was observed 222 between the two sampling occasions. As can be seen in Table 1, variations in VS and COD 223 values of the two municipal food waste (RW-FW) samples were 20 and $65 \%$, respectively. 
224 The co-digestion ratio of 5\% (wt/wt) was suitable for both occasions. Temporal variation in 225 VS and COD content (10 and 90\%, respectively) could also be seen with the two commercial 226 food waste (PM-FW) samples. Nevertheless, the two commercial food waste (PM-FW) 227 samples did not display any inhibition even at the co-digestion ratio of $15 \%(\mathrm{wt} / \mathrm{wt})$. Whilst 228 the dilution conducted prior to collection (section 2.1) proved effective in reducing the 229 inhibition potential, at the same co-digestion ratio the maximum achieved biogas production 230 was lower than that of municipal food waste (RW-FW). Both RW-FW and PM-FW are food 231 waste materials. In other words, the original co-substrate of PM-FW prior to dilution would 232 be expected to be similar in composition to that of RW-FW, and thus, they would result in 233 similar methane productions. Thus, higher co-digestion ratio between PM-FW and sludge 234 would be required to validate the effectiveness of dilution of this co-substrate.

235 The BMP results from the co-digestion of paper waste (Figure 4b) show a continual increase 236 in biogas production as the co-digestion ratio increased. It is possible that the rate of paper 237 waste hydrolysis (that is responsible for the production of volatile fatty acid) is slow. Thus, a 238 high co-digestion ratio of paper waste and sludge did not result in volatile fatty acid 239 accumulation in the system. It is also noteworthy that the benefit of adding additional concentrations beyond 5\% was negligible.

242 The removal efficiencies for TS, VS and COD were evaluated for the different co-substrates. 243 All solid wastes show a tendency for incomplete removal of these parameters (Table 2), 244 indicating that these waste materials may result in additional sludge production and may 245 negatively affect sludge stabilization targets. The only exception was RW-FW 2 (council 246 food waste), for which high removal efficiencies for TS and VS were observed. Paper waste 247 also displayed some positive results in terms of the removal of both VS and COD. However, 248 a lower TS removal indicates that paper waste might also result in additional sludge 249 production.

250 The additional methane yields were calculated based on the best BMP results of these co251 substrates (Table 2). As expected, all solid waste materials evaluated in this study produce 252 less methane than dehydrated algae (139 $\mathrm{L} \mathrm{CH}_{4} / \mathrm{kg}$ of algae). 


\subsection{Co-digestion with Liquid Wastes}

255 All liquid wastes displayed highly reproducible BMP results. This high level of reproducibility is consistent with several previous studies (Angelidaki et al., 2009; Koch et al., 2015a). The results confirm the validity of BMP as a screening tool for co-substrate evaluation.

Organic overloading was observed with beverage reject at co-digestion ratio of $10 \%(\mathrm{wt} / \mathrm{wt})$

260 (Figure 5a). The inhibition of beverage reject waste beyond a co-substrate concentration of $10 \%$ was attributed to the rapidly degradable organics in the substrate. The sugar content of non-alcoholic beverage reject can be quickly converted into organic acids, which in turn impact upon the digester $\mathrm{pH}$. This premise could be demonstrated through a more systematic co-digestion evaluation using a semi-continuous anaerobic digester. Each of the other cosubstrates showed a nearly proportionate increase in biogas production with regards to cosubstrate concentration.

\section{[FIGURE 5]}

The digestion performance in terms of VS and COD removals when co-digesting with liquid wastes was generally much higher compared to solid wastes (section 3.3). In fact, not only did the addition of co-substrate result in no additional VS and COD residual, synergistic removal of COD, VS and TS were also observed with all liquid co-substrates with the exception of FOG. In other words, the observed COD, VS, and TS removals of above 100\% were attributed to the synergistic effect of liquid waste co-digestion. The lower digestion performance involving FOG is likely related to its higher lipid content. Co-digestion of lipid rich wastes complicates considerations with issues such as lipid floatation, long chain fatty acid accumulation, pre-treatment requirements and lower degradation rates ( $\mathrm{Li}$ et al., 2013; Wan et al., 2011). The synergistic removal efficiencies observed in the co-digestion of the other wastes signifies a potential reduction in sludge production and improvement in the final biosolids stability.

\section{[TABLE 3]}

\section{Conclusions}

282 In this study, algae and seven organic waste materials were evaluated as potential cosubstrates for anaerobic digestion with sewage sludge for their bio-methane potential and likely influence on digested sludge quality in term of TS, VS and COD. All co-substrates 
increased the bio-methane yield by three to six times compared with conventional anaerobic digestion of sewage sludge. While solid/slurry co-substrates resulted in notable more methane gas production, they are associated with a higher risk of organic overloading. The maximum co-digestion ratios were identified for most solid/slurry co-substrates including algae (6\% $\mathrm{wt} / \mathrm{wt})$, undiluted food waste $(5 \% \mathrm{wt} / \mathrm{wt})$, untreated bakery waste $(5 \%)$, and diluted commercial food waste $(10 \% \mathrm{wt} / \mathrm{wt})$. On the other hand, the maximum co-digestions ratio of beverage reject and sewage sludge was $10 \%(\mathrm{wt} / \mathrm{wt}$ ). Elevated concentrations of sulphur and phosphorous were observed in all food waste co-substrates from both municipal and commercial sources. In addition, with bakery waste being the only exception, the codigestion of all other solid co-substrates resulted in additional VS and COD residuals in digested sludge. By contrast, most liquid co-substrates evaluated here showed a notable synergistic effect, which enhanced the removals of TS, VS and COD during anaerobic digestion.

\section{Acknowledgements}

Stewart Ramsay and his team at the Sydney Water's Wollongong Wastewater Treatment Plant are gratefully acknowledged for their assistance with sewage sludge sample collection. This research was supported under Australian Research Council's Linkage Project funding scheme (project LP150100304).

\section{References}

Angelidaki, I., Alves, M., Bolzonella, D., Borzacconi, L., Campos, J.L., Guwy, A.J., Kalyuzhnyi, S., Jenicek, P., van Lier, J.B. 2009. Defining the biomethane potential (BMP) of solid organic wastes and energy crops: a proposed protocol for batch assays. Water Science and Technology, 59, 927-934.

Appels, L., Baeyens, J., Degreve, J., Dewil, R. 2008. Principles and potential of the anaerobic digestion of waste-activated sludge. Progress in Energy and Combustion Science, 34, $755-781$.

Chynoweth, D.P., Owens, J.M., Legrand, R. 2001. Renewable methane from anaerobic digestion of biomass. Renewable Energy, 22, 1-8.

Dewil, R., Baeyens, J., Roels, J., Van De Steene, B. 2009. Evolution of the total sulphur content in full-scale wastewater sludge treatment. Environmental Engineering Science, 26, 867-872.

Edwards, J., Othman, M., Burn, S. 2015a. A review of policy drivers and barriers for the use of anaerobic digestion in Europe, the United States and Australia. Renewable and Sustainable Energy Reviews, 52, 815-828. 
Edwards, J.A., Burn, S., Othman, M. 2015b. Anaerobic Digestion at Wastewater Treatment Plants: Opportunities with and without Policy Support. Water, 83-88.

Esposito , G., Frunzo, L., Giordano, A., Liotta, F., Panico, A., Pirozzi, F. 2012. Anaerobic Co-Digestion of Organic Wastes. Review Environmental Science Biotechnology 325341.

Fersi, S., Chtourou, N., Jury, C., Poncelet, F. 2014. Economic analysis of renewable heat and electricity production by sewage sludge digestion-a case study. International Journal of Energy Research, 39, 234-243.

Giuliano, A., Bolzonella, D., Pavan, P., Cavinato, C., Cecchi, F. 2013. Co-digestion of livestock effluents, energy crops and agro-waste: Feeding and process optimization in mesophilic and thermophilic conditions. Bioresource Technology, 128, 612-618.

Haider, M.R., Zeshan, Yousaf, S., Malik, R.N., Visvanathan, C. 2015. Effect of mixing ratio of food waste and rice husk co-digestion and substrate to inoculum ratio on biogas production. Bioresource Technology, 190, 451-457.

Holm-Nielsen, J.B., Al Seadi, T., Oleskowicz-Popiel, P. 2009. The future of anaerobic digestion and biogas utilization. Bioresource Technology, 100, 5478-5484.

Kim, M.-H., Kim, J.-W. 2010. Comparison through a LCA evaluation analysis of food waste disposal options from the perspective of global warming and resource recovery. Sci. Total Environ., 408, 3998-4006.

Koch, K., Fernandez, Y.B., Drewes, J.E. 2015a. Influence of headspace flushing on methane production in Biochemical Methane Potential (BMP) tests. Bioresource Technology, $186,173-178$.

Koch, K., Helmreich, B., Drewes, J.E. 2015b. Co-digestion of food waste in municipal wastewater treatment plants: Effect of different mixtures on methane yield and hydrolysis rate constant. Applied Energy, 137, 250-255.

Li, C., Champagne, P., Anderson, B.C. 2013. Effects of ultrasonic and thermo-chemical pretreatments on methane production from fat, oil and grease (FOG) and synthetic kitchen waste in anaerobic co-digestion. Bioresource Technology, 130, 187-197.

Li, D., Liu, S., Mi, L., Li, Z., Yuan, Y., Yan, Z., Liu, X. 2015. Effects of feedstock ratio and organic loading rate on the anaerobic mesophilic co-digestion of rice straw and cow manure. Bioresour. Technol., 189, 319-326.

Mata-Alvarez, J., Dosta, J., Romero-Guiza, M.S., Fonoll, X., Peces, M., Astals, S. 2014. A critical review on anaerobic co-digestion achievements between 2010 and 2013. Renewable and Sustainable Energy Reviews, 36, 412-427.

McKennedy, J., Sherlock, O. 2015. Anaerobic digestion of marine macroalgae: A review. Renewable and Sustainable Energy Reviews, 52, 1781-1790.

Montingelli, M.E., Tedesco, S., Olabi, A.G. 2015. Biogas production from algal biomass: A review. Renewable and Sustainable Energy Reviews, 43, 961-972. 
Nghiem, L.D., Nguyen, T.T., Manassa, P., Fitzgerald, S.K., Dawson, M., Vierboom, S. 2014. Co-digestion of sewage sludge and crude glycerol for on-demand biogas production. International Biodeterioration and Biodegradation, 95, 160-166.

Park, K., Lee, H., Phelan, S., Liyanaarachchi, S., Marleni, N., Navaratna, D., Jegatheesan, V., Shu, L. 2014. Mitigation strategies of hydrogen sulphide emission in sewer networks - A review. International Biodeterioration \& Biodegradation, 95, Part A, 251-261.

Pavan, P., Bolzonella, D., Battistoni, E., Cecchi, F. 2007. Anaerobic co-digestion of sludge with other organic wastes in small wastewater treatment plants: an economic considerations evaluation. Water Science and Technology, 56, 45-53.

Prochazka, J., Dolejs, P., Maca, J., Dohanyos, M. 2012. Stability and inhibition of anaerobic processes caused by insufficiency or excess of ammonia nitrogen. Bioenergy and Biofuels, 93, 439-447.

Sabbag, H., Brenner, A., Nikolski, A., Borojovich, E.J.C. 2015. Prevention and control of struvite and calcium phosphate precipitation by chelating agents. Desalination and Water Treatment, 55, 61-69.

Shen, Y., Linville, J.L., Urgun-Demirtas, M., Mintz, M.M., Synder, S.W. 2015. An overview of biogas production and utilization at full-scale wastewater treatment plants (WWTP) in the United States: Challenges and opportunities toward energy-neutral WWTP. Renewable and Sustainable Energy Reviews, 50, 346-362.

Silvestre, G., Fernandez , B., Bonmati, A. 2015. Significance of anaerobic digestion as a source of clean energy in wastewater treatment plants. Energy Conservation and Management, 101, 255-262.

Tchobanoglous, G., Burton, F.L. 1991. Wastewater engineering: treatment, disposal, and reuse / Metcalf \& Eddy, Inc. McGraw-Hill, New York.

Wan, C., Zhou, Q., Fu, G., Li, Y. 2011. Semi-continuous anaerobic co-digestion of thickened waste activated sludge and fat, oil and grease. Waste Management, 31, 1752-1758.

Wang, M., Sahu, A.K., Rusten, B., Park, C. 2013. Anaerobic co-digestion of microalgae Chlorella sp. and waste activated sludge. Bioresource Technology, 142, 585-590.

Weiland, P. 2010. Biogas Production: Current State and Perspectives. Appl Microbiol Biotechnol (2010) 849-860.

Yaich, H., Garna, H., Besbes, S., Paquot, M., Blecker, C., Attia, H. 2011. Chemical composition and functional properties of Ulva lactuca seaweed collected in Tunisia. Food Chem., 128, 895-901.

Yang, S., McDonald, J., Hai, F.I., Price, W.E., Khan, S.J., Nghiem, L.D. 2016. Occurence of trace organics contaminants in wastewater sludge and their removals by anaerobic digestion. Bioresource Technology. (Accepted 28 Dec 2015) dx.doi.org/10.1016/j.biortech.2015.12.080. 
Table 1: Key properties of sludge and co-substrates (NA = no analysis; RW-FW = municipal food waste from a local council; PM-FW =

396 commercial food waste from a commercial collector; UBW = untreated bakery waste; BJ = non-alcoholic beverage reject; TBW = treated bakery

397 waste; DW = waste from a dairy processor; $F O G=$ fat-oil-grease).

\begin{tabular}{|c|c|c|c|c|c|c|c|c|c|c|}
\hline \multirow{2}{*}{ Parameter } & \multirow{2}{*}{ Sludge } & \multicolumn{5}{|c|}{$\begin{array}{l}\text { Solid organic waste } \\
\end{array}$} & \multicolumn{4}{|c|}{ Liquid organic waste } \\
\hline & & RW-FW 1 & RW-FW 2 & PM-FW 1 & PM-FW 2 & UBW & BJ & TBW & DW & FOG \\
\hline TS $(\mathrm{g} / \mathrm{L})$ & 16 & 135.7 & 194.4 & 36.5 & 39.6 & 175.6 & 52.1 & 51 & 65.9 & 25 \\
\hline VS (g/L) & 15 & 102.1 & 121.3 & 29.4 & 32.6 & 170.8 & 48.1 & 18.9 & 48.9 & 20.3 \\
\hline $\operatorname{COD}(g / L)$ & 20.1 & 179.6 & 296.8 & 122.9 & 11.4 & 17.5 & 81.1 & 47.4 & 65.9 & 25.0 \\
\hline$S(\mathrm{mg} / \mathrm{L})$ & 285.5 & NA & 3450 & 140 & 2350 & NA & 49.8 & 242 & 310 & 201 \\
\hline$P(\mathrm{mg} / \mathrm{L})$ & 657.5 & 3660 & 3710 & 472 & 3250 & NA & 68.4 & 306 & 456 & 668 \\
\hline
\end{tabular}

Table 2: Performance of solid waste co-digestion with sewage sludge.

\begin{tabular}{|l|c|c|c|c|c|}
\hline Parameters & PW & RW-FW 1 & RW-FW 2 & PM-FW 1 & UBW \\
\hline $\mathrm{CH}_{4}$ (L/kg substrate) & 35 & $73.1 \pm 0.19$ & $127.1 \pm 8.0$ & $30.9 \pm 5.7$ & 68.5 \\
\hline TS Removal (\%) & 96 & 85.8 & 104.4 & 2.8 & 89.0 \\
\hline VS Removal (\%) & 102 & 88.1 & 207.6 & 68.0 & 94.8 \\
\hline COD Removal (\%) & 107 & 88.4 & 80.4 & 38.3 & 105.4 \\
\hline
\end{tabular}

399 Table 3: Performance of solid waste co-digestion with sewage sludge.

\begin{tabular}{|l|c|c|c|c|}
\hline Parameters & BJ & TBW & DW & FOG \\
\hline $\mathrm{CH}_{4}$ (L/kg substrate) & $26 \pm 1.16$ & $27 \pm 5.6$ & $94 \pm 40.4$ & $47 \pm 2.8$ \\
\hline COD Removal (\%) & 141 & 119 & 102 & 108 \\
\hline VS Removal (\%) & 116 & 219 & 218 & 72 \\
\hline TS Removal (\%) & 133.9 & 366.2 & 119.3 & 84.2 \\
\hline
\end{tabular}




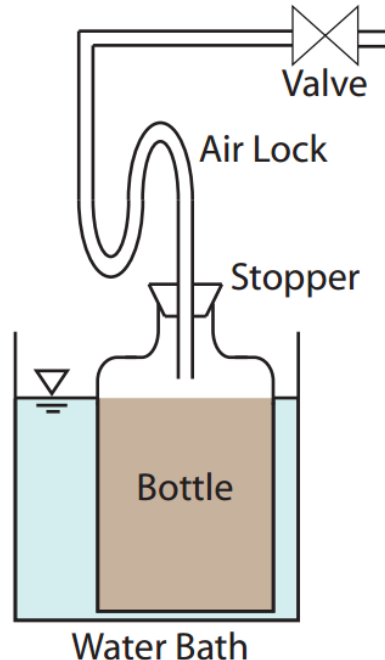

Water Bath

401

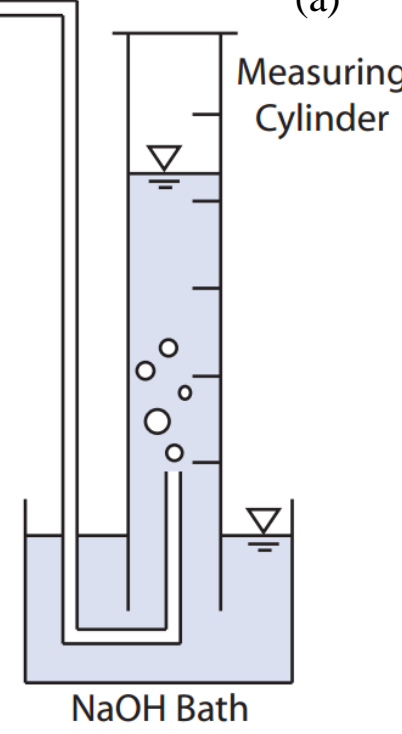

(b)

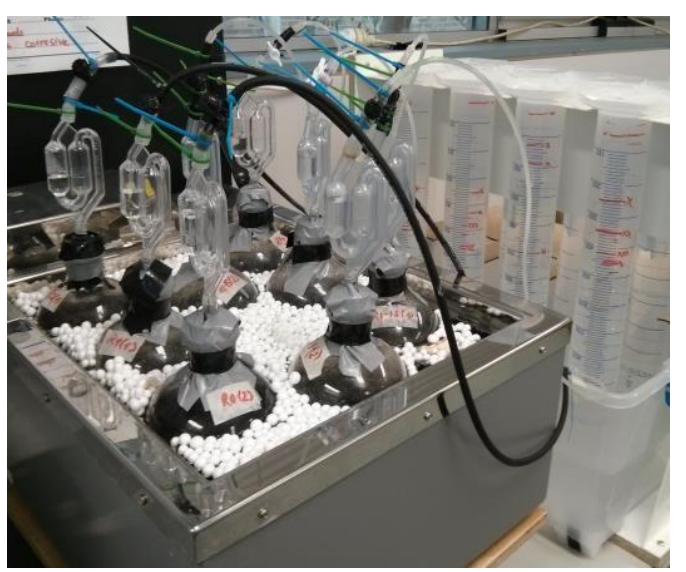

$\mathrm{NaOH}$ Bath

402 Figure 1: Bio-methane potential experimental equipment: (a) Schematic diagram and (b) 403 Photograph.
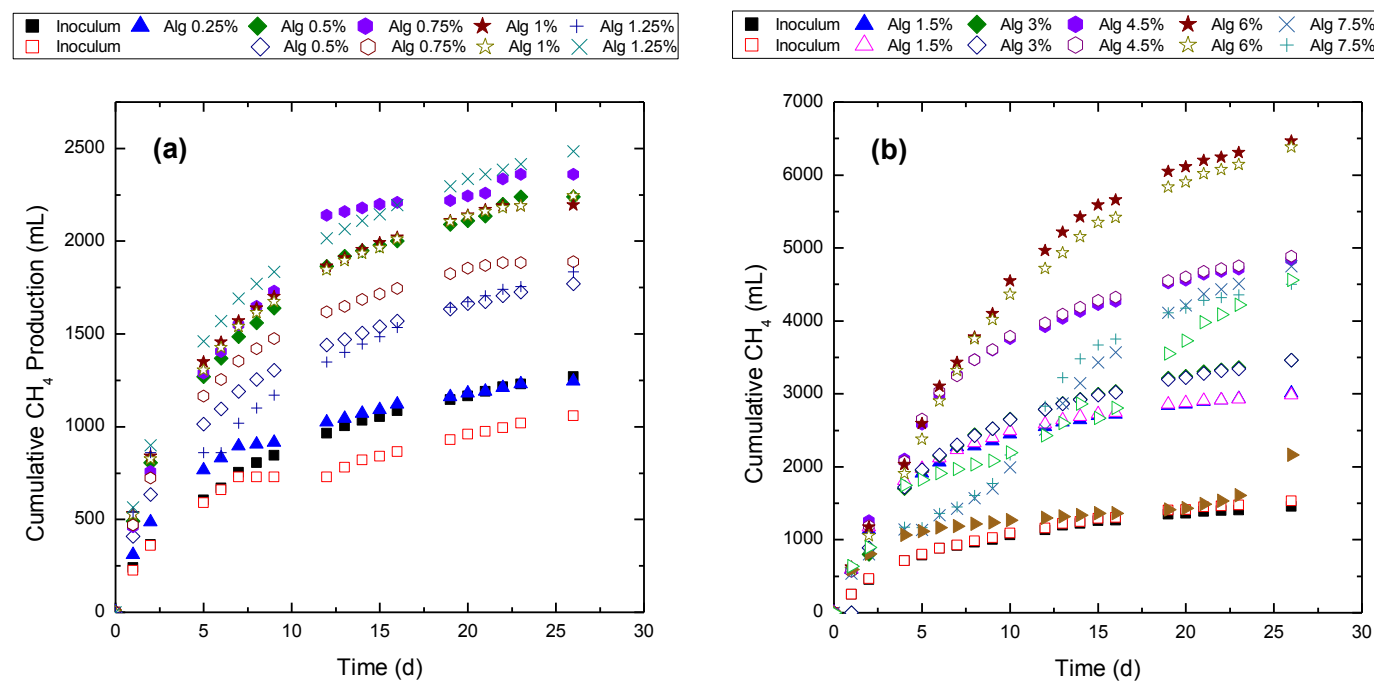

404

405 Figure 2: Cumulative methane production from a combination of algae and sewage sludge as 406 a function of time. 


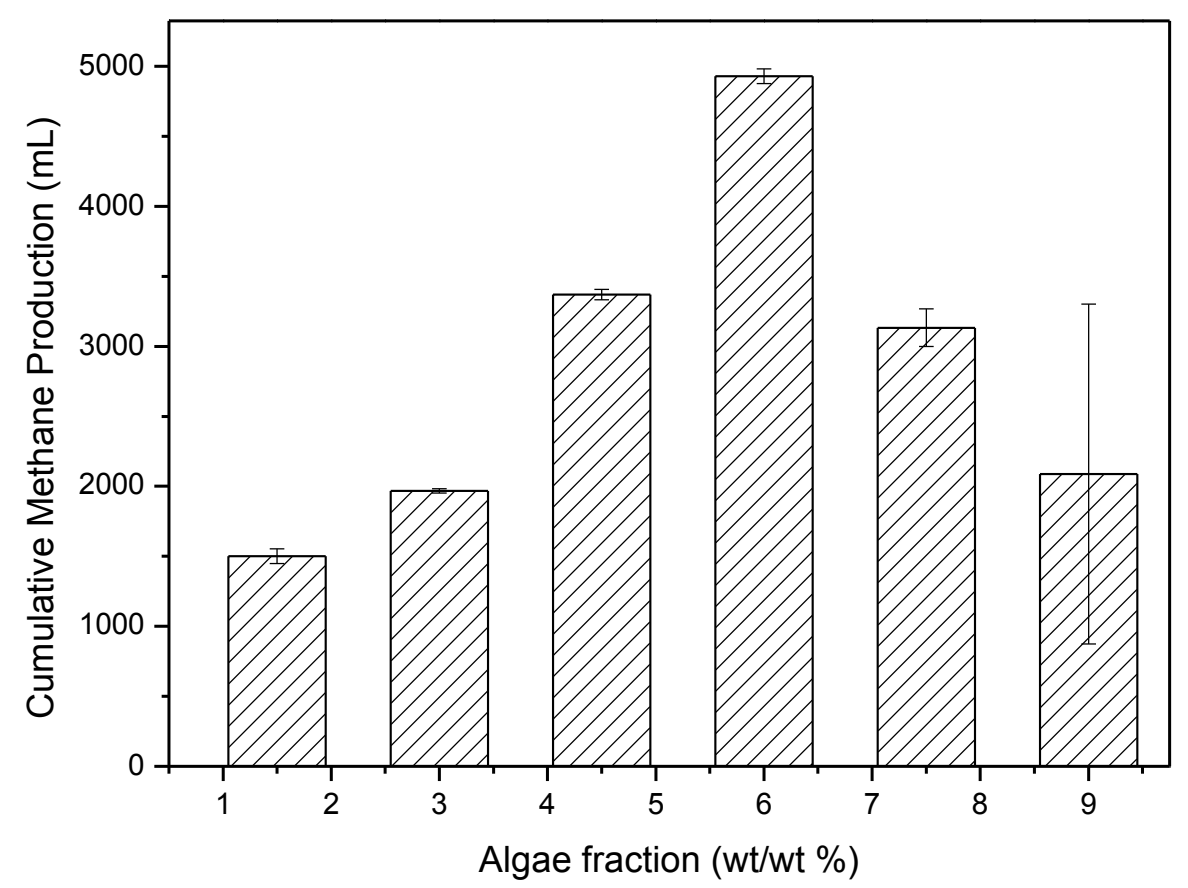

407

408 Figure 3: Cumulative methane production plotted against algae fraction (error bars are 409 standard deviations from duplicate experiments).
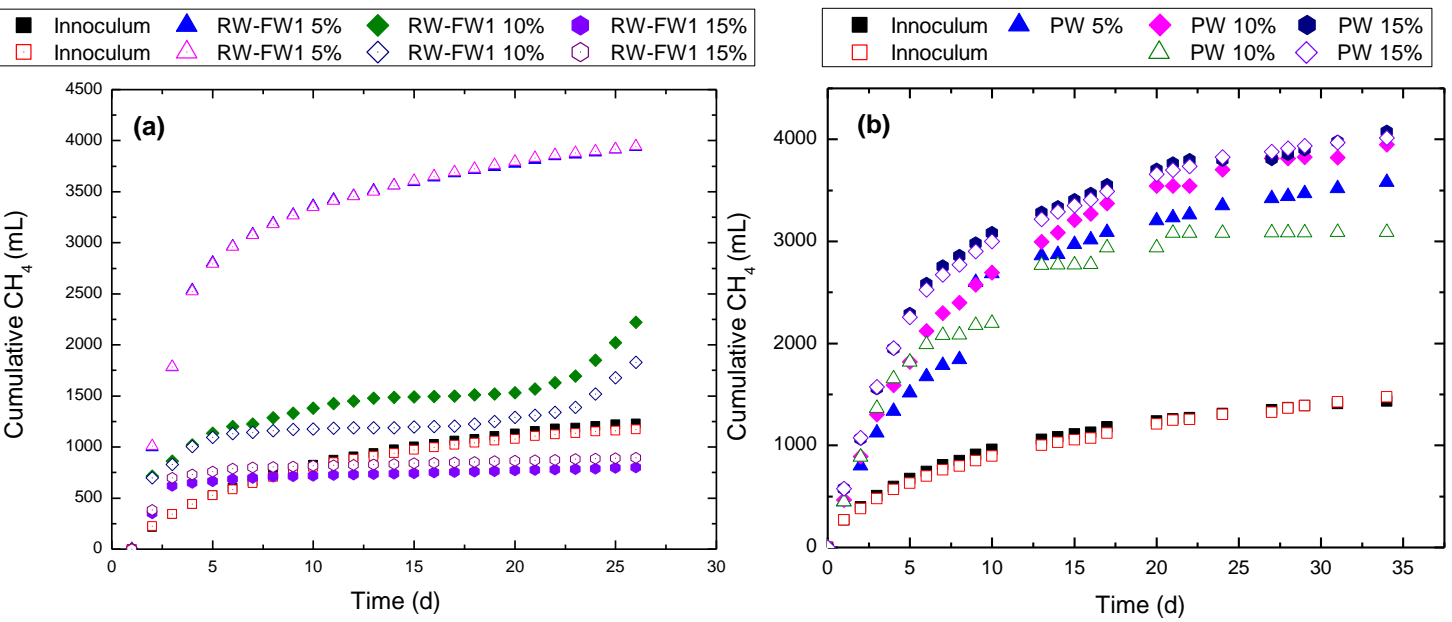

410

411 Figure 4: Cumulative methane production plotted against time for co-digestion of council 412 food waste (RW-FW) and paper waste (PW) as co-substrates. 

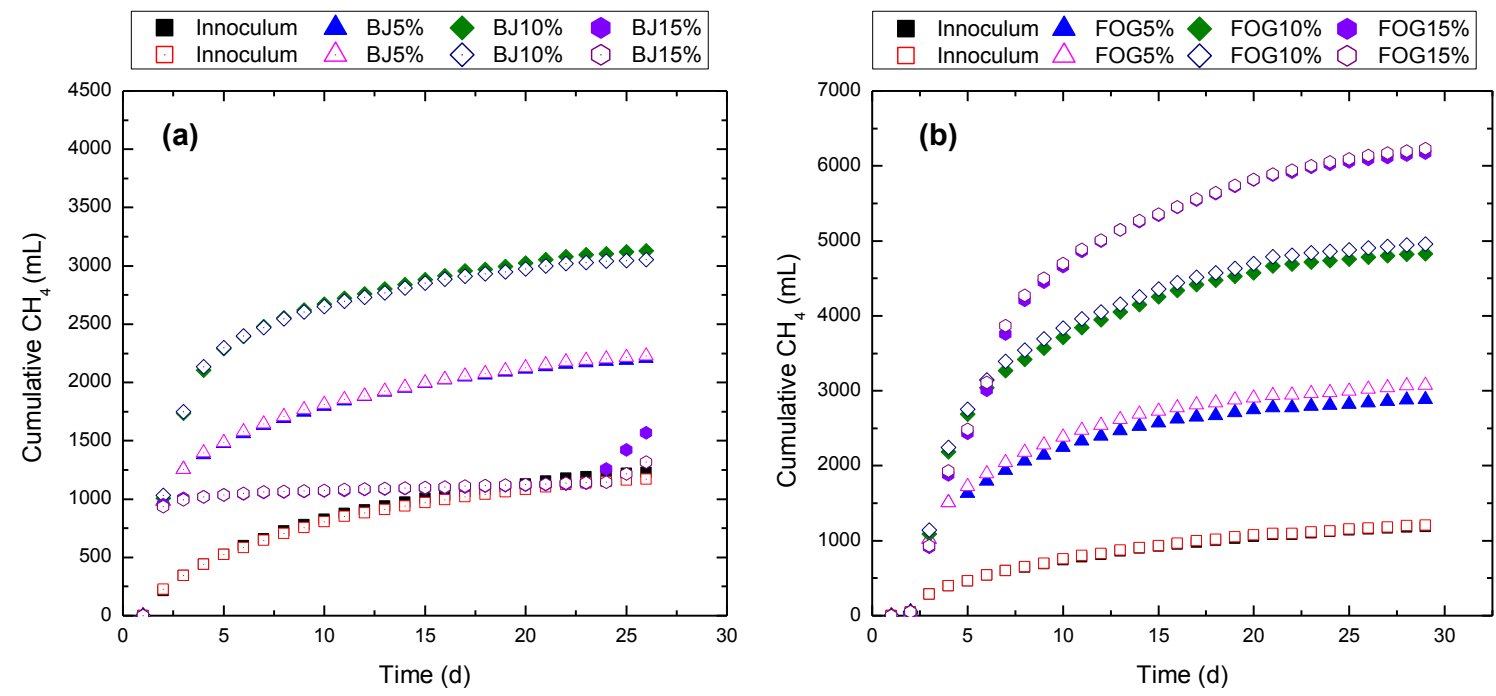

413

414 Figure 5: Cumulative methane production plotted against time for co-digestion of beverage 415 reject (BJ) and fat oil and grease (FOG) wastes as co-substrates. 